\title{
Neuromatch Academy: a 3-week, online summer school in computational neuroscience
}

't Hart BM ${ }^{1}$; Achakulvisut T ${ }^{2}$; Adeyemi $\mathrm{A}^{3}$; Akrami $\mathrm{A}^{4}$; Alicea B ${ }^{5}$; Alonso-Andres $\mathrm{A}^{6}$; Alzate-Correa $\underline{\mathrm{D}}^{7}$; Ash $\mathrm{A}^{8}$; Ballesteros $\mathrm{JJ}^{9}$; Balwani $\mathrm{A}^{10}$; Batty $\mathrm{E}^{11}$; Beierholm U ${ }^{12}$; Benjamin $\mathrm{AS}^{2}$; Bhalla $\mathrm{U}^{13}$; Blohm G ${ }^{14}$; Blohm JCH ${ }^{14}$; Bonnen $\mathrm{K}^{15}$; Brigham $\mathrm{M}^{16}$; Brunton $\mathrm{BW}^{17}$; Butler $\mathrm{JS}^{18}$; CCNSS ${ }^{19}$; Caie

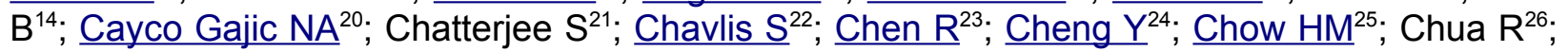
Dai ${ }^{27}$; David I ${ }^{28}$; DeWitt EEJ ${ }^{29}$; Denis J ${ }^{30}$; Dipani ${ }^{31}$; Dorschel $A^{32}$; Drugowitsch J ${ }^{33}$; Dwivedi $\mathrm{K}^{34}$; Escola $\mathrm{S}^{35}$; Fan $\mathrm{H}^{36}$; Farhoodi $\mathrm{R}^{2}$; Fei $\mathrm{Y}^{37}$; Fiquet $\mathrm{PE}^{38}$; Fontolan $\mathrm{L}^{39}$; Forest $\mathrm{J}^{40}$; Fujishima $\mathrm{Y}^{41}$; Galbraith BV ${ }^{42}$; Galdamez ${ }^{43}$; Gao R ${ }^{44}$; Gjorgjieva J ${ }^{45}$; Gonzalez A ${ }^{46}$; Gu Q ${ }^{47}$; Guo Y ${ }^{48}$; Guo $\underline{Z}^{49}$; Gupta PK ${ }^{25}$; Gurbuz $\mathrm{BT}^{50}$; Haimerl $\mathrm{C}^{38}$; Harrod $\mathrm{JB}^{51}$; Hyafil $\mathrm{A}^{52}$; Irani $\mathrm{M}^{53}$; Jacobson $\mathrm{D}^{54}$; Johnson $\mathrm{M}^{2}$; Jones $\mathrm{IS}^{2}$; Karni $\mathrm{G}^{55}$; Kass $\mathrm{RE}^{56}$; Kim $\mathrm{HE}^{57}$; Kist $\mathrm{AM}^{58}$; Koene $\mathrm{R}^{59}$; Kording $\mathrm{K}^{2}$; Krause MR ${ }^{60}$; Kumar ${ }^{61}$; Kühn NK ${ }^{62}$; LC RAY ${ }^{63}$; Laporte ML ${ }^{14}$; Lee J ${ }^{64}$; Li S ${ }^{65}$; Lin S ${ }^{66}$; Lin Y ${ }^{67}$; Liu $\mathrm{S}^{2}$; Liu T ${ }^{2}$; Livezey JA ${ }^{68}$; $\mathrm{Lu} \mathrm{L}^{69}$; Macke $\mathrm{JH}^{70}$; Mahaffy $\mathrm{K}^{71}$; Martins $\mathrm{AL}^{72}$; Martorell $\mathrm{N}^{73}$; Martínez $\mathrm{M}^{74}$; Mattar $\mathrm{MG}^{75}$; Menendez $\mathrm{JA}^{76}$; Miller KD${ }^{77}$; Mineault PJ; Mohammadi $\mathrm{N}^{78}$; Mohsenzadeh $\mathrm{Y}^{79}$; Morgenroth $\mathrm{E}^{80}$; Morshedzadeh $\mathrm{T}^{81}$; Mosberger $\mathrm{AC}^{77}$; Muliya $\mathrm{M}^{82} ;$ Mur $\mathrm{M}^{79}$; Murray $\mathrm{JD}^{47}$; $\underline{\mathrm{ND} \mathrm{Y}}^{83}$; $\underline{\text { Naud }}^{84}$; Nayak $\mathrm{P}^{85}$; Oak $\mathrm{A}^{86}$; Olivos Castillo $\mathrm{I}^{37}$; Orouji $\mathrm{S}^{24}$; Otero-Millan $\mathrm{J}^{87}$; Pachitariu $\mathrm{M}^{88}$; Pandey $\mathrm{B}^{17}$; Paredes $\mathrm{R}^{89}$; Parent ${ }^{90}$; Park IM $^{91}$; Peters MAK ${ }^{24}$; Pitkow $\mathrm{X}^{43,37}$; Poirazi P ${ }^{22}$; Popal ${\underline{H^{92}}}^{92}$ Prabhakaran $\mathrm{S}^{93}$; Qiu T ${ }^{94}$; Ragunathan $\mathrm{S}^{95}$; Rodriguez-Cruces $\mathrm{R}^{96}$; Rolnick ${ }^{26}$; Sahoo AK $^{97}$; Salehinajafabadi $\mathrm{S}^{98}$; Savin $\mathrm{C}^{38}$; Saxena $\mathrm{S}^{99}$; Schrater $\mathrm{P}^{100}$; Schroeder $\mathrm{K}^{77}$; Schwarze $\mathrm{AC}^{17}$; Sedigh-Sarvestani $\mathrm{M}^{101}$; Sekhar $\mathrm{KY}^{102}$; Shadmehr $\mathrm{R}^{103}$; Shanechi $\mathrm{MM}^{104}$; Sharma $\mathrm{S}^{105}$; Shea-

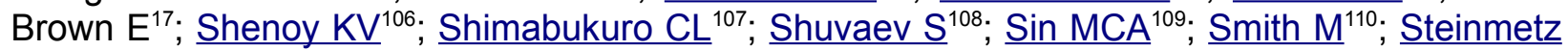
$\mathrm{NA}^{17}$; Stosio $\mathrm{K}^{111}$; Straley $\mathrm{E}^{43}$; Strandquist $\mathrm{G}^{17}$; Stringer $\mathrm{C}^{88}$; Tomar $\mathrm{R}^{112}$; Tran $\mathrm{N}^{108}$; Triantafillou $\underline{S}^{113}$; Udeigwe $\mathrm{L}^{114}$; Valeriani $\mathrm{D}^{33}$; Valton $\mathrm{V}^{115}$; Vaziri-Pashkam $\mathrm{M}^{116}$; Vincent $\mathrm{P}^{117}$; Vishne $\mathrm{G}^{118}$; Wallisch $\mathrm{P}^{38}$; Wang $\mathrm{P}^{119}$; Ward $\mathrm{C}^{120}$; Waskom $\mathrm{M}^{38}$; Wei $\mathrm{K}^{121}$; Wu $\mathrm{A}^{122}$; Wu $\mathrm{Z}^{43}$; Wyble ${ }^{123}$; Zhang $\underline{\underline{L}}^{124} ; \underline{\text { Zysman }} \mathrm{D}^{125} ; \underline{\text { d'Oleire Uquillas }}^{126} ;$ van Viegen $\mathrm{T}^{126}$

1: CVR, York University, Toronto 2: University of Pennsylvania, Philadelphia 3: Square wave Limited 4: Sainsbury Wellcome Centre, University College London 5: Orthogonal Research and Education Laboratory 6: Neuroscience Institute of Alicante 7: The Ohio State University, Columbus. 8: Smartalpha.Al, Ankara 9: Massachusetts General Hospital, Boston, MA. 10: Georgia Institute of Technology 11: Harvard University 12: Durham University, England 13: National Centre for Biological Sciences, Tata Institute of Fundamental Research, Bangalore, India 14: Center for Neuroscience Studies, Queen's University, Kingston, Ontario 15: New York University, New York City 16: Narrativa Comum Lda 17: University of Washington, Seattle 18: TU Dublin, School of Mathematical Sciences, City Campus, Dublin Ireland 19: Computational and Cognitive Neuroscience Summer School: https://www.ccnss.org/ 20: Ecole Normale Supérieure, PSL University, Paris 21: University College London (presently Laboratoire Jean Perrin, Sorbonne Université) 22: Institute of Molecular Biology and Biotechnology (IMBB), Foundation for Research and Technology-Hellas (FORTH), Greece 23: Massachusetts Institute of Technology 24: University of California, Irvine 25: The University of British Columbia, Vancouver, Canada 26: McGill University \& Mila, Montreal 27: East China Normal University, Shanghai 28: National Autonomous University of Mexico 29: Champalimaud Research, Lisbon 30: INMED, Marseille 31: Upload AI LLC 32: ETH Zürich 33: Harvard Medical School, Boston MA 34: Goethe University Frankfurt 35: Columbia University 36: Harvard University, Cambridge, MA, USA 37: Rice University 38: New York University 39: Howard Hughes Medical Institute 40: New York University, New York 41: Kyushu University 42: Talla, Inc 43: Baylor College of Medicine 44: University of California San Diego 45: Max Planck Institute for Brain Research, Frankfurt, Germany 46: Stanford University 47: Yale University 48: Johns Hopkins University, Baltimore MD 49: Brandeis University 50: Bilkent University, Turkey 51: Harvard-MIT Health Sciences and Technology, Cambridge MA 52: Centre de Recerca Matemàtica, Spain 53: Neurodynamics of Cognition Laboratory, School of Medicine, Pontificia Universidad Catolica de Chile 54: Lockheed Martin 55: Minerva schools at KGI 56: Carnegie Mellon University 57: University of Delaware 58: 1Division of Phoniatrics and Pediatric Audiology, Department of Otorhinolaryngology, Head \& Neck Surgery, University Hospital Erlangen, Friedrich-Alexander-University Erlangen-Nürnberg, Waldstr. 1, 91054 Erlangen, Germany 59: Carboncopies Brain Research Foundation, San Francisco 60: Montreal Neurological Institute, McGill University 61: KTH Royal Institute of Technology, Stockholm, Sweden 62: Neuro-Electronics 
Research Flanders empowered by imec, VIB and KU Leuven 63: City University of Hong Kong 64: Ecole Normale Supérieure, Paris, France 65: School of Mathematical Sciences, MOE-LSC, and Institute of Natural Sciences, Shanghai Jiao Tong University, Shanghai, China 66: University of California, Santa Barbara 67: Tsinghua University 68: Lawrence Berkeley National Laboratory 69: Peking University, Suoxinda 70: University of Tübingen and Max Planck Institute for Intelligent Systems 71: University of Connecticut 72: Champalimaud Center for the Unknown 73: University of Buenos Aires 74: Universitat de Barcelona 75: University of California, San Diego 76: Gatsby Computational Neuroscience Unit, University College London 77: Columbia University, New York 78: Institute for Advanced Studies in Basic Sciences (IASBS) 79: Western University, London, ON 80: Ecole Polytechnique Federale Lausanne 81: University of Toronto, Toronto 82: SASTRA Deemed University, Thanjavur, India 83: PES University, Bengaluru 84: University of Ottawa, Ottawa 85: King's College London 86: University of Houston 87: University of California, Berkeley 88: HHMI Janelia Research Campus 89: The University of Edinburgh 90: Orthogonal Research and Education Lab, Champaign-Urbana, IL USA 91: Stony Brook University 92: Temple University, Philadelphia 93: Moffitt Cancer Center, Florida 94: Institute of Neuroscience, Chinese Academy of Science, Shanghai 95: Cactus Communication, India 96: McGill University 97: National Institute of Science Education and Research, India 98: Bernstein Center for Computational Neuroscience. Berlin 99: University of Florida, Gainesville, FL 100: University of Minnesota, Minneapolis MN 101: Max Planck Florida Institute for Neuroscience 102: Freelance Machine Learning Consultant 103: Johns Hopkins University 104: University of Southern California 105: Blue Marble Space Institute of Science, Seattle, Washington, USA 106: Departments of Electrical Engineering, Bioengineering and Neurobiology, Stanford University, Stanford CA 94305 and Howard Hughes Medical Institute at Stanford University, Stanford, CA 94305 107: University of Buenos Aires, Argentina 108: Cold Spring Harbor Laboratory 109: Cornell University 110: Harvard University, School of Engineering and Applied Sciences, Cambridge MA 111: Volkswagen Group Machine Learning Research Lab, Munich 112: Czech Academy of Sciences, Prague 113: University of Pittsburgh 114: Manhattan College 115: University College London 116: National Institute of Mental Health 117: Sainsbury Wellcome Centre 118: The Hebrew University, Jerusalem, Israel 119: Arizona State University, Tempe, AZ 120: Albert Einstein College of Medicine 121: Peking University 122: Columbia University, USA 123: Penn State University, State College, PA 124: Department of Cognition, Emotion, and Methods in Psychology, Faculty of Psychology, University of Vienna, Vienna, Austria 125: DeepLearning.AI 126: Princeton Neuroscience Institute, Princeton University, NJ, USA

\section{Summary}

Neuromatch Academy (https://neuromatch.io/academy) was designed as an online summer school to cover the basics of computational neuroscience in three weeks. The materials cover dominant and emerging computational neuroscience tools, how they complement one another, and specifically focus on how they can help us to better understand how the brain functions. An original component of the materials is its focus on modeling choices, i.e. how do we choose the right approach, how do we build models, and how can we evaluate models to determine if they provide real (meaningful) insight. This meta-modeling component of the instructional materials asks what questions can be answered by different techniques, and how to apply them meaningfully to get insight about brain function.

Each day constitutes one teaching module and covers one topic in computational neuroscience (see table 1). While the content is organized as a 3-week crash-course $(+2$ optional Python introduction days) of consecutive teaching modules that build on one another, it can be rolled out at any pace, in its entirety or as stand-alone parts (provided prerequisites for each part are met). Materials consist of highly curated recorded lectures and tutorials, organized in 'days', as well as 5 data sets for group projects. Most days can be used as separate, independent modules and can, for example, be combined with other instructional content. To facilitate this, we not only provide general prerequisites for the entire course but also daily topic-specific prerequisites (see appendix 1). The material is meant to either be taught to small groups of $\sim 10$ attendees guided by a teaching assistant, for instruction in a classroom, or for usage in other (potentially for-profit) events. As such the material is largely self sufficient and could be used for self-study. 


\section{Week 1}

W1D1 Model Types

W1D2 Modeling Practice

W1D3 Model Fitting

W1D4 Machine Learning:

GLM

W1D5 Dimensionality

Reduction
Week 2

W2D1 Bayesian Statistics

W2D2 Linear Systems

W2D3 Decision Making

W2D4 Optimal Control

W2D5 Reinforcement

Learning
Week 3

W3D1 Real Neurons

W3D2 Dynamic Networks

W3D3 Network Causality

W3D4 Deep Learning 1

W3D5 Deep Learning 2

Table 1. Neuromatch Academy Topics. Organized chronologically by week (W) and day of week (D), e.g. week 2 day $4=$ W2D4. In addition, there are two days of preparatory instruction in coding Python, the materials for which can be found in WOD1.

Each instruction module (day) consists of 1 ) an introductory lecture ( $\sim 30$ minutes) that broaches the topic to students and explains the general approach, followed by 2) hands-on tutorials in the form of several ipython notebooks ( 3 hours) with code-completion assignments and answers, and further instruction through embedded micro-lectures, and finally 3$)$ an outro lecture ( 30 minutes) to recapitulate the covered material and provide an outlook on its applicability to neuroscience research. All lectures and tutorials are available online [permalink]. Each day is meant to instruct the basics of a given topic and further readings are supplied.

For attendees to apply what they learn, we also provide materials for individual or group projects and five curated data sets (see table 2) to use for these projects, including videos describing the data and ipython notebooks to get started.

\begin{tabular}{|c|c|c|}
\hline Data set & Contains & Possible projects \\
\hline Stringer data & $\begin{array}{l}\text { activity from } \sim 10,000 \mathrm{~V} 1 \text { neurons, } \\
\text { recorded with calcium imaging from a } \\
\text { mouse in total darkness }\end{array}$ & $\begin{array}{l}\text { discover structure of cortical column; } \\
\text { relate activity to spontaneous behavior }\end{array}$ \\
\hline $\begin{array}{l}\text { Steinmetz } \\
\text { data }\end{array}$ & $\begin{array}{l}\text { neuropixels recording (waveforms, } \\
\text { task events, spikes) in mice doing a } \\
\text { visual discrimination task }\end{array}$ & $\begin{array}{l}\text { predict task performance from neural } \\
\text { data; reconstruct face, eye or paw } \\
\text { movement from neural data }\end{array}$ \\
\hline $\begin{array}{l}\text { Kay/Gallant } \\
\text { data }\end{array}$ & $\begin{array}{l}\text { fMRI during viewing of natural } \\
\text { images }\end{array}$ & $\begin{array}{l}\text { reconstruct or predict images from brai } \\
\text { activity in separate regions }\end{array}$ \\
\hline HCP data & $\begin{array}{l}\text { fMRI time series in } 7 \text { tasks and } \\
\text { resting state for } 340 \text { human } \\
\text { participants, and percellation in ROIs }\end{array}$ & $\begin{array}{l}\text { identify a set of brain areas differentiall } \\
\text { involved in various tasks }\end{array}$ \\
\hline IBL data & $\begin{array}{l}\text { very large behavioral data of mice } \\
\text { doing a visual detection task with a } \\
\text { bias }\end{array}$ & $\begin{array}{l}\text { fit models to predict the choice of the } \\
\text { animal; model individual differences }\end{array}$ \\
\hline
\end{tabular}

Table 2. Data sets for group projects. The data sets available through the Neuromatch Academy repository. 


\section{Statement of Need}

\section{Need for training}

Neuroscience makes use of a broad range of computational techniques, but very few institutions have enough local expertise to provide meaningful instruction in all of them. As a result, most computational neuroscience researchers around the world lack appropriate training and we aim to provide that here. Additionally, by focussing on meta-modeling, i.e. which method to apply in which situation, we assure that computational methods will be used in such a way as to lead to meaningful new insights into brain function.

\section{Need for accessible materials}

Neuroscience, like any academic discipline, struggles to be more diverse and inclusive, in the social sense. We aim to remove some of the barriers to good educational materials for computational neuroscience. By making the material freely available online, we make them available to anyone worldwide; we thus remove the need to be part of geographically restricted, rich, prestigious institutions to gain access to high-level training (e.g. the notebooks have been mirrored on gitee and videos on bilibili to make the material more accessible in China). Freely accessible materials should also alleviate negative effects of systemic biases and gatekeeping leading to discrimination in access to resources. A further step towards increased diversity is made by having diverse lecturers who may serve as role models. Finally, we have added captions in English and translated them in Mandarin and Spanish for both people with hearing difficulties and those who are not fluent in English (YouTube metrics indicate $\sim 35 \%$ of views use captions). While our efforts do not achieve full inclusivity and diversity in neuroscience, we believe it is a step in the right direction.

\section{Experience}

A first step in building an accessible content base was to recruit a pool of lecturers and content creators with an eye towards maximizing diversity in dimensions such as gender, race and career status. This helps to reduce intrinsic forms of bias within the lectures and exercises, and also helps to broadcast the accessibility of the discipline to a wider audience.

The materials (intro, outro and micro-lectures as well as tutorials) went through several instances of quality control, before we used it in our own summer school. First, a group of content reviewers provided feedback on the material which was integrated by the primary content creators. Second, a group of skilled programmers served as tutorial editors who went through the tutorials to review and edit code and make sure it all adhered to our standards. For example, they made sure code was as simple as possible and that all plots used the same look. Third, two separate groups of content testers independently went through all the material as if they were students, providing feedback to tutorial writers who integrated this feedback. They reported errors and omissions and provided pedagogical advice on confusing or misleading parts to the rest of the team. They also made sure the micro-lectures connected with the material in the tutorials. For example, we made sure the hands-on tutorials are do-able within the time frame, while providing bonus materials for faster attendees. After this step, videos of lectures were finalized. Fourth, the tutorial and code editors once again made sure all tutorials worked, used the same style and connected with the rest of the material. For future rounds of our summer school, we also had content testers provide structured feedback on the material 
during the actual summer school, and about $\sim 90 \%$ of attendees and TA's filled in end-of-day surveys during the actual summer school. We will use this feedback to further improve the materials. The most recent version can be found on GitHub (https://github.com/NeuromatchAcademy/).

Our quality-control processes ensured that the course content was well received. During the summer of 2020, we taught the Neuromatch Academy material to 1757 interactive students in 64 countries with 191 teaching assistants. There were also $\sim 6000$ registered observer students (more according to YouTube analytics). The summer school ran 24/7 across all timezones with no major glitches. The percentage of interactive students that completed at least $50 \%$ of classes was $86 \%$. Of all end-of-day survey respondents, $94 \%$ would recommend NMA to a friend.

\section{Acknowledgements}

The Neuromatch Academy summer school also crucially relied on many teaching assistants, mentors and people organizing the community. Many of these people provided valuable feedback which will be used to improve the material and experience in coming summer schools. We wish to thank everyone involved in making NMA a success! 


\section{Appendix 1: Prerequisites}

For self-study or mixing the NMA course content with other content, we provide a list of prerequisites for each day of content (table A1). The overall prerequisites are described in the repository, with readings for self-study.

Day Topic Prerequisites

W0D1 Python Introduction

W1D1 Model Types

W1D2 Modeling Practice

W1D3 Model Fitting

W1D4 Machine Learning: GLM
Basic probability
Linear algebra (vectors, matrices) and calculus (derivatives)

Basic knowledge of linear algebra, probability, and neuroscience

Basic neuroscience knowledge

Basic python

Basic neuroscience knowledge

Knowledge of Model Types

Knowledge of linear algebra and convex optimization

Encoding, model fitting eigenvectors

W2D1 Bayesian Statistics

W2D2 Linear Systems

W2D3 Decision Making

W2D4 Optimal Control
Basics of probability

Basic normative models

Basics of predictive models and their evaluation

Basics of constructing models

Basics of linear algebra: eigenvalue

Basics of calculus: derivatives and integrals

Understanding of mean and covariance

Bayes' rule

Markov Chains

Basic probability

Bayes' rule

Markov Chains, linear stochastic dynamics

Hidden Markov Models, Kalman filter
W1D3

NMA prereqs

NMA prereqs

NMA prereqs

How they are

met

NMA prereqs

NMA prereqs

NMA prereqs

NMA prereqs

W1D1

NMA prereqs

Prereqs of NMA

W1D2

W1D3

W1D2

NMA prereqs

NMA prereqs

NMA prereqs

W2D1

W2D2

NMA prereqs

W2D1

W2D2

W2D3 


\begin{tabular}{|c|c|c|c|}
\hline \multirow[t]{2}{*}{ Day } & \multirow[t]{2}{*}{ Topic } & Prerequisites & $\begin{array}{l}\text { How they are } \\
\text { met }\end{array}$ \\
\hline & & Basic probability & NMA prereqs \\
\hline \multirow[t]{4}{*}{ W2D5 } & \multirow[t]{4}{*}{ Reinforcement Learning } & State spaces & W2D2 \\
\hline & & Markov Decision Processes & W2D3, W2D4 \\
\hline & & Bayesian statistics & W2D1 \\
\hline & & Optimal Control & W2D4 \\
\hline \multirow[t]{4}{*}{ W3D1 } & \multirow[t]{4}{*}{ Real Neurons } & Knowledge of Model Types & W1D1 \\
\hline & & Basics of calculus: ODE & NMA prereqs \\
\hline & & $\begin{array}{l}\text { Understanding of elementary statistics } \\
\text { and random processes, correlations }\end{array}$ & $\begin{array}{l}\text { NMA prereqs, } \\
\text { W2D2 }\end{array}$ \\
\hline & & $\begin{array}{l}\text { Basic neuroscience knowledge: } \\
\text { Neurons, spikes and synapses (not } \\
\text { necessarily the mathematical models) }\end{array}$ & NMA prereqs \\
\hline \multirow[t]{3}{*}{ W3D2 } & \multirow[t]{3}{*}{ Dynamic Networks } & Knowledge of Model Types & W1D1 \\
\hline & & Basics of calculus: ODE & NMA prereqs \\
\hline & & $\begin{array}{l}\text { Basic linear algebra: vectors, matrices, } \\
\text { eigenvectors }\end{array}$ & NMA prereqs \\
\hline W3D3 & Network Causality & Basics of regression & W1D3, W1D4 \\
\hline \multirow[t]{3}{*}{ W3D4 } & \multirow[t]{3}{*}{ Deep Learning 1} & $\begin{array}{l}\text { Cross-validation and model fitting basics } \\
\text { with linear models }\end{array}$ & W1D3 \\
\hline & & Matrix multiplication & NMA prereqs \\
\hline & & Correlation matrices & NMA prereqs \\
\hline \multirow[t]{3}{*}{ W3D5 } & \multirow[t]{3}{*}{ Deep Learning 2} & Some knowledge of DL & W3D4 \\
\hline & & Dimensionality reduction & W1D5 \\
\hline & & Gradient descent & W3D4 \\
\hline
\end{tabular}

Table A1: Prerequisites for each module of Neuromatch Academy. This can be used to guide self study or help integrate the material with other content. 


\section{Appendix 2: Author Contributions}

Team
Curriculum Design \&
Management

Group Projects

Day Coordinators

Micro-Lecturers

Tutorial writers

Code Editing \& Management

\section{Members}

Akrami A; Blohm G; Bonnen K; DeWitt EEJ; Escola S; Hyafil A;

Kording K; Kumar A; Macke JH; Mineault PJ; Murray JD; Peters MAK; Pitkow X; Schrater P; Stringer C; Valton V; Wallisch P; Wyble B; d'Oleire Uquillas $F$; van Viegen $T$

Akrami A, Alicea B, Butler JS, DeWitt EEJ, Gupta PK, LC RAY, Lee J, Mohammadi N, Murray JD, Pachitariu M, Parent J, Pitkow X, Rodriguez-Cruces R, Saxena S, Schrater P, Sharma S, Steinmetz "NA", Straley E, Strandquist G, Valton V, Waskom M, Zhang L

W0D1: Brigham M, W1D2: Blohm G, W1D3: Hyafil A, W1D4: Macke JH, W1D5: Murray JD, W2D1: Kording K, W2D2: Brunton BW, W2D3: Wallisch P, W2D4: Pitkow X, W2D5: DeWitt EEJ, W3D1: Kumar A, W3D2: Kumar A, W3D3: Kording K, W3D4: Stringer C, W3D5: DeWitt EEJ

Intro \& Outro Lecturers W0D1: Brigham M, W1D1: Blohm G, Peters MAK, W1D2: Blohm G, Peters MAK, W1D3: Drugowitsch J, Wei K, W1D4: Park IM, Savin C, W2D1: Kording K, Schrater P, Pitkow X, W2D2: Shea-Brown E, Shenoy KV, W2D3: Escola S, Shanechi MM, W2D4: Shadmehr R, Smith M, W3D1: Bhalla U, Poirazi P, W3D2: Miller KD, W3D3: Kording K, Kass RE, Triantafillou S, W3D4: Johnson M, Mur M, W3D5: Rolnick $\mathrm{D}$

W0D1: Brigham M, W1D1: Kording K, W1D2: Blohm G, Schrater P, W1D3: Wu A, W1D4: Wu A, W1D5: Cayco Gajic NA, W2D1: Kording K, Valton V, W2D2: Brunton BW, W2D3: Fei Y, W2D4: Pitkow X, W2D5: DeWitt EEJ, Mattar MG, W3D1: Naud R, W3D2: Gjorgjieva J, W3D3: Kording K, Liu T, W3D4: Stringer C, Mohsenzadeh Y, W3D5: Brigham M

W0D1: Brigham M, CCNSS " ", W1D1: Kording K, Galbraith BV, Laporte ML, W1D2: Blohm G, Schrater P, 't Hart BM, W1D3: Fiquet PÉ, Galbraith BV, W1D4: Benjamin AS, Fiquet PÉ, W1D5: Murray JD, Cayco Gajic "NA", W2D1: Kording K, Valton V, Krause MR, W2D2: Brunton BW, Pandey B, Schwarze AC, Strandquist G, Pitkow X, W2D3: Fei Y, Galbraith BV, Haimerl C, Livezey JA, Pitkow X, W2D4: Schrater P, Saxena S, Wu Z, Pitkow X, W2D5: DeWitt EEJ, Galbraith BV, Krause MR, Mattar MG, W3D1: Kumar A, Murray JD, Gu Q, Li S, W3D2: Kumar A, Murray JD, Gjorgjieva J, Gu Q, Li S, W3D3: Kording K, Benjamin AS, Liu T, W3D4: Stringer C, Menendez JA, W3D5: DeWitt EEJ, Brigham M

Bonnen, K; Batty, E; Chavlis, S; Dwivedi, K; Farhoodi, R; Fontolan, L; Galbraith, BV; Gao, R; Krause, MR; Kording, K; Kühn, NK; Livezey, JA; Laporte, ML; Mineault, PJ; Parent, J; Pandey, B; Pitkow, X; Sedigh-Sarvestani, M; Sharma, S; Salehinajafabadi, S; Strandquist, G; Valton, V; Waskom, M; Wu, Z 


\section{Team}

Quality Control \& Testing

Copyright Checks \& Corrections

Video Editing

Captioning

Spanish Translations

Mandarin Translations

\section{Members}

Alicea, B; Bonnen, K; Balwani, A; Beierholm, U; Butler, JS; Cheng, Y; Chua, R; Caie, B; David, I; DeWitt, EEJ; Dipani, A; Farhoodi, R; Gupta, PK; Gonzalez, A; Jones, IS; Jacobson, D; Kording, K; Koene, R; Kist, AM; Kim, HE; LC, RAY; Laporte, ML; Lu, L; Morshedzadeh, T; Martorell, N; Orouji, S; Oak, A; Olivos Castillo, I; Popal, H; Paredes, R; Prabhakaran, S; Pitkow, X; Parent, J; Rodriguez-Cruces, R;

Schroeder, K; Sharma, S; Stosio, K; Salehinajafabadi, S; Sedigh-

Sarvestani, M; Strandquist, G; Tomar, R; Udeigwe, L; Vaziri-Pashkam, M; Valeriani, D; Zysman, D; Zhang, L

Blohm, G; Jacobson, D; Karni, G; Kording, K; LC, RAY; Martorell, N; Morgenroth, E; Parent, J; Park, IM; Sedigh-Sarvestani, M; Stringer, C; Shuvaev, S; Tran, N; Udeigwe, L; Ward, C

Adeyemi, A; Ash, A; Alicea, B; Blohm, JCH; d'Oleire Uquillas, F; Fujishima, Y; Forest, J; Gurbuz, BT; Harrod, JB; Irani, M; Lin, S; Mohammadi, N; Mineault, PJ; Nayak, P; Oak, A; Qiu, T; Valeriani, D; van Viegen, T; Vaziri-Pashkam, M

Blohm, JCH; Chow, HM; Chatterjee, S; Dorschel, A; Denis, J; Fan, H; Martins, AL; Mosberger, AC; Muliya, M; Mahaffy, K; ND, Y; Olivos Castillo, I; Ragunathan, S; Sekhar, KY; Sin, MCA; Sahoo, AK; Vishne, G

Alzate-Correa, D; Alonso-Andres, A; Ballesteros, JJ; Galdamez, M; Martínez, M; Otero-Millan, J; Shimabukuro, CL; Vincent, P

Chen, R; Chow, HM; Dai, Y; Fan, H; Guo, Y; Guo, Z; Lin, Y; Liu, S; Wang, $P$

Table A2: Contributions of Neuromatch Academy content creators. 